\title{
Positive end-expiratory pressure attenuates
}

\section{hemodynamic effects induced by an overload of inspiratory muscles in patients with COPD}

This article was published in the following Dove Press journal: International Journal of COPD

6 October 2017

Number of times this article has been viewed

\author{
Flavia Schaper-Magalhães' \\ José Felippe Pinho' \\ Carolina Andrade Bragança \\ Capuruço² \\ Maria Glória Rodrigues- \\ Machado' \\ 'Medical Sciences Faculty of Minas \\ Gerais, Post-Graduation Program \\ in Health Sciences, Belo Horizonte, \\ Brazil; '2Department of Cardiology, \\ Clinics Hospital, Federal University of \\ Minas Gerais, Belo Horizonte, Brazil
}

Correspondence: Maria Glória

Rodrigues-Machado

Faculdade Ciências Médicas-Minas

Gerais, Pós-Graduação em Ciências da

Saúde, 30130-II 0 Alameda Ezequiel

Dias 275-Centro, Belo Horizonte,

Minas Gerais, Brazil

Tel +55 3I 32487229

Fax +55 31 32487221

Email maria.machado@

cienciasmedicasmg.edu.br
Background: Inspiratory muscle training (IMT) using a Threshold ${ }^{\circledR}$ device is commonly used to improve the strength and endurance of inspiratory muscles. However, the effect of IMT, alone or with positive end-expiratory pressure (PEEP), on hemodynamic parameters in patients with chronic obstructive pulmonary disease (COPD) remains unknown.

Objective: To assess the effects of an overload of inspiratory muscles using IMT fixed at 30\% of the maximal inspiratory pressure (MIP), and IMT associated with $5 \mathrm{cmH}_{2} \mathrm{O}$ of PEEP (IMT + PEEP), on the echocardiographic parameters in healthy subjects and patients with COPD.

Methods: Twenty patients with COPD (forced expiratory volume in 1 second 53.19 \pm 24.71 pred $\%$ ) and 15 age-matched healthy volunteers were evaluated using spirometry, MIP, the COPD assessment test (CAT), and the modified Medical Research Council (mMRC) dyspnea scale. The E- (fast-filling phase) and A- (atrial contraction phase) waves were evaluated at the tricuspid and mitral valves during inspiration and expiration in the following sequence: at basal conditions, using IMT, and using IMT + PEEP.

Results: Patients with COPD had reduced MIPs versus the control group. Ten patients had CAT scores $<10$ and 12 patients had $m M R C$ scores $<2$. E-wave values at the mitral valve were significantly decreased with IMT during the inspiratory phase in both groups. These effects were normalized with IMT + PEEP. During the expiratory phase, use of IMT + PEEP normalized the reduction in E-wave values in the COPD group. During inspiration at the tricuspid valve, reduction in E-wave values during IMT was normalized by IMT + PEEP in COPD group. During the expiratory phase, the value of the E-waves was significantly reduced with overload of the inspiratory muscles in both groups, and these effects were normalized with IMT + PEEP. A-waves did not change under any conditions.

Conclusion: Acute hemodynamic effects induced by overloading of the inspiratory muscles were attenuated and/or reversed by the addition of PEEP in COPD patients.

Keywords: echocardiography, mitral valve, tricuspid valve, inspiratory muscle strength, spirometry, Medical Research Council, dyspnea scale

\section{Introduction}

Patients with chronic obstructive pulmonary disease (COPD) have lung hyperinflation, which can occur due to the loss of lung elastic recoil, airflow limitations, or insufficient expiratory time to fully exhale the tidal volume. The air that is trapped creates positive end-expiratory pressure (PEEP), known as intrinsic PEEP (PEEPi) or auto-PEEP, ${ }^{1,2}$ which is even greater during periods when the disease is exacerbated. ${ }^{3}$ PEEPi has been described as an additional load to be overcome by the inspiratory muscles, requiring the generation of a negative pressure equal in magnitude to PEEPi in order to initiate 
inspiratory flow. ${ }^{2,4}$ PEEPi varies in accordance with the severity of the disease and can be directly correlated with the functional residual capacity and inversely correlated with the forced expiratory volume in the first second $\left(\mathrm{FEV}_{1}\right){ }^{5}$ Thus, the increased work demanded by the respiratory muscles, and their subsequent overload, in patients with COPD may induce respiratory fatigue..$^{2,3,6,7}$ Pulmonary hyperinflation also compromises the performance of the respiratory muscles, reducing their ability to generate tension. ${ }^{8,9}$ This respiratory muscle dysfunction is associated with increased risk of hospitalization and premature death. ${ }^{10}$

COPD causes permanent changes in the lung parenchyma, and has hemodynamic repercussions, such as pulmonary hypertension, left ventricular dysfunction, and atherosclerosis, leading to significant morbidity and worsening of the prognosis of the disease. ${ }^{11}$ The increase in intrathoracic pressure caused by PEEPi reduces both the preload of the right and left ventricles and left ventricular compliance, and can increase right ventricular afterload and pulmonary vascular resistance. ${ }^{2,12}$ In addition to hypertrophy, the right ventricle of patients with COPD showed a reduction of the ejection fraction, that is, a decline in the performance of the systolic pumping action of the right ventricle. ${ }^{13}$ Major variations in intrathoracic pressure and lung volume have acute hemodynamic effects, directly influencing venous return. ${ }^{14-16}$ Echocardiography, a simple, cost-effective, noninvasive assessment method, ${ }^{16}$ is able to detect cardiac abnormalities and acute hemodynamic effects. ${ }^{11}$ In a recent study, Houben-Wilke et a ${ }^{17}$ evaluated 514 patients referred to pulmonary rehabilitation and demonstrated that more than half of these had echocardiographic abnormalities.

The training of respiratory muscles is an important component of pulmonary rehabilitation ${ }^{18,19}$ and provides significant clinical improvements, such as increased inspiratory muscle strength and endurance, tolerance to physical activity, reduced shortness of breath, and improved quality of life..$^{20}$ The PEEP valve has been used in pulmonary rehabilitation programs in order to increase the expiratory flow of patients with COPD, and thus reduce lung hyperinflation. ${ }^{21,22}$ The aim of our study was to evaluate whether the association of the PEEP valve and overload of the inspiratory muscles would promote changes in ventricular filling patterns.

\section{Materials and methods Study design}

This observational, cross-sectional, controlled study was conducted at the clinic of the Faculty of Medical Sciences of Minas Gerais and at the Conrad - Diagnóstico por Imagem, from March to August 2015. Individuals between the ages of 50 and 80 years were included in the study, of which 20 patients diagnosed with COPD were in the case group and 15 healthy subjects were in the control group, following clinical examination and confirmation of normal pulmonary function. The diagnosis of COPD was made in accordance with the 2015 Global Strategy for Diagnosis, Management, and Prevention of COPD (Global initiative for chronic Obstructive Lung Disease [GOLD]) guidelines. ${ }^{23}$ Patients with COPD were classified as GOLD I-IV. The modified British Medical Research Council (mMRC) dyspnea scale and the COPD assessment test (CAT) questionnaire were used to assess the shortness of breath and quality of life, respectively. Both methods were previously validated for the Brazilian population. ${ }^{24,25}$ Besides the diagnosis of COPD, the inclusion criteria were clinical stability, absence of infection or exacerbation of disease in the past 4 weeks, and absence of severe heart diseases (ventricular systolic dysfunction, previous cardiac surgery, congenital cardiac malformation, arrhythmia, moderate to severe valvar heart disease, or heart failure) or other comorbidities that could affect the study protocol. The exclusion criteria were pulmonary diseases other than COPD, significant thoracic deformity, neuromuscular diseases, sequelae of neurological diseases, cardiovascular instability (recent myocardial infarction, significant arrhythmias, ventricular systolic dysfunction, previous cardiac surgery, congenital cardiac malformation, moderate to severe heart disease, or heart failure), recent thoracic or abdominal surgeries, diabetes mellitus, chronic kidney disease, and a history of liver failure. Moreover, patients with cognitive impairment that prevented them from performing the tests, women with breast implants, and those with a body mass index $(\mathrm{BMI})>35 \mathrm{~kg} / \mathrm{m}^{2}$ were also excluded from the study.

The Research Ethics Committee of the Faculty of Medical Sciences of Minas Gerais (CEPCM-MG) approved the study (reference number 758.360). All patients provided written informed consent.

\section{Selection of participants}

Participants were selected on the basis of the medical records of the Clinical Medicine and Pneumology departments of the Faculty of Medical Sciences of Minas Gerais (Figure 1). Out of the 71 medical records from the Clinical Medicine Department analyzed, only 15 subjects met the inclusion criteria and they were allocated to the control group. For the experimental group, 340 medical records from the Pneumology Department were analyzed, including 116 patients diagnosed with COPD. Eightyfour patients were excluded owing to severity of the disease, 


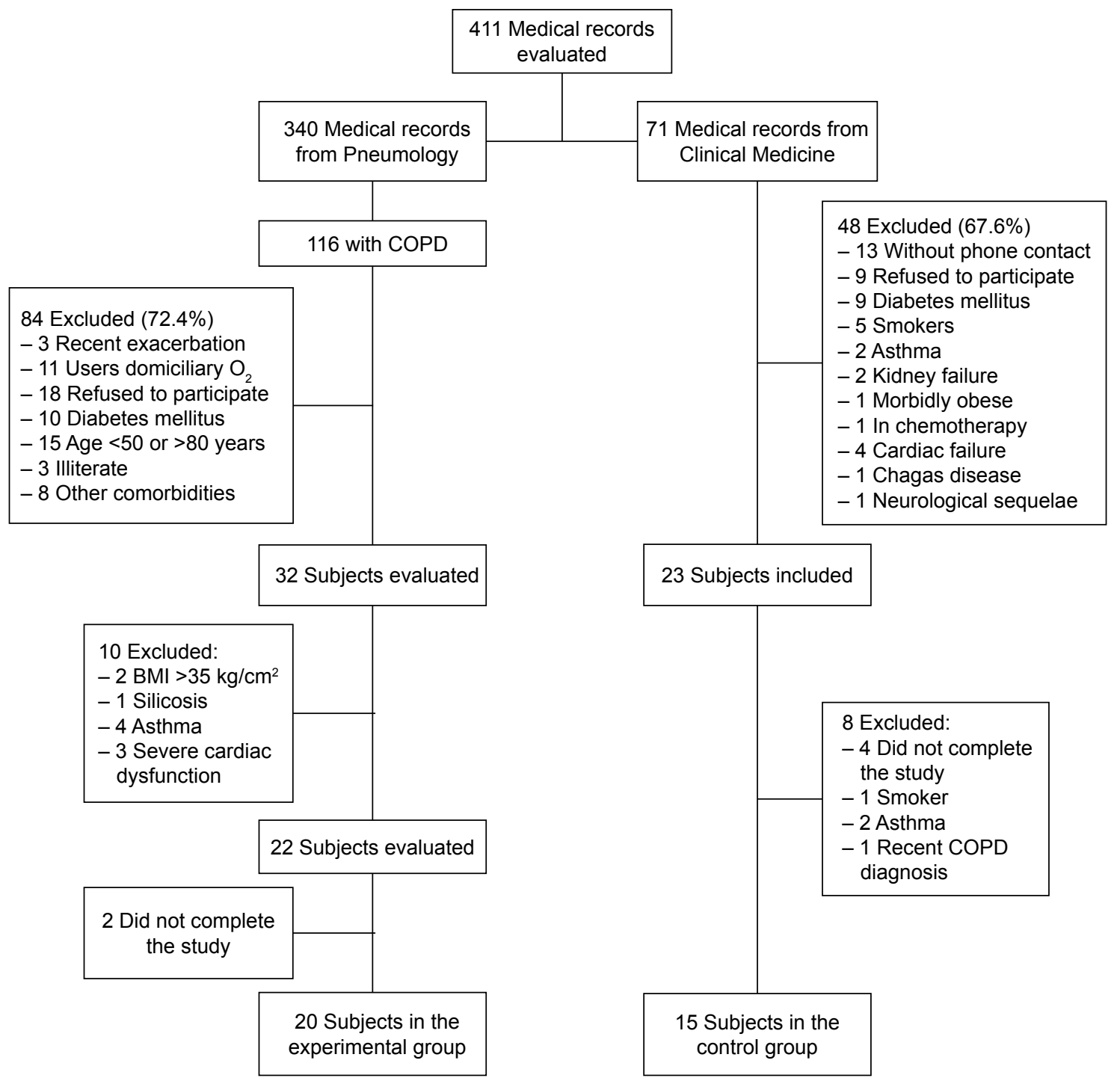

Figure I Selection of participants for the control and COPD groups.

Abbreviations: BMI, body mass index; COPD, chronic obstructive pulmonary disease

illiteracy, and/or other associated comorbidities. Thirty-two patients were evaluated and 10 were excluded from the study for the following reasons: five with other pulmonary diseases, two morbidly obese, and three with heart disease. Twenty-two patients fulfilled all the inclusion criteria of the study, and only two among them did not complete the study. Therefore, the experimental group consisted of 20 participants with COPD.

\section{Experimental protocol}

At the first session, all participants underwent a pulmonary function test, and patients with COPD also underwent a bronchodilator test. After 15 minutes of rest, the maximal inspiratory pressure (MIP) was measured. Then, the participants were familiarized with the Threshold ${ }^{\circledR}$ inspiratory muscle training (IMT) set at 30\% MIP, both with and without
PEEP, in order to become acquainted with the instrument and the procedure that would be used during echocardiography. In addition, the participants in the experimental group answered two questionnaires: CAT to evaluate the impact of the disease on their daily life, and mMRC to assess the level of dyspnea. At the second session, the echocardiographic examination was performed over three different procedures: basal respiration without inspiratory overload and without the PEEP valve (sham device), respiration with inspiratory overload of $30 \%$ MIP, and respiration with overload associated with the PEEP valve (IMT + PEEP), in that order.

\section{Pulmonary function test}

The pulmonary function test was performed in both the control and experimental groups, according to the guidelines 
of the American Thoracic Society/European Respiratory Society, ${ }^{26}$ using the Spirolab ${ }^{\circledR}$ spirometer (Medical International Research, Rome, Italy). The bronchodilator test was performed only in the experimental group. Medication was discontinued 8-12 hours before spirometry was performed. The same examiner performed all pulmonary function tests. The equations proposed by Pereira et $\mathrm{al}^{27}$ were used to calculate the predicted values.

\section{Assessment of strength of the inspiratory muscles}

MIP was evaluated in both groups from the residual volume using a MVD300 digital manometer (Globalmed ${ }^{\circledR}$, Porto Alegre - RS, Brazil). The participants were evaluated in a sitting position at $90^{\circ}$, with their feet on the floor. At least five measurements were performed for each participant, with an interval of 1 minute rest between each maneuver. The MIP value used was the highest from the five maneuvers, providing that the difference between the two highest measurements did not exceed 5\%. The equations proposed by Pereira ${ }^{28}$ were used to calculate the predicted values.

Following the evaluation of MIP, participants were familiarized with the Threshold ${ }^{\circledR}$ IMT (Respironics HealthScan, Inc, Parsippany, NJ, USA) using 30\% of the aforementioned MIP, with or without $5 \mathrm{cmH}_{2} \mathrm{O} \mathrm{PEEP}$, in a randomized order, with 5 minutes between measurements (Figure 2).

\section{Dyspnea assessment and CAT}

The CAT questionnaire was used to evaluate symptoms in subjects with COPD. ${ }^{25,29}$ It is composed of eight items: cough, sputum production, chest tightness, shortness of breath, limitations in household activities, confidence in leaving the house, sleep, and energy.

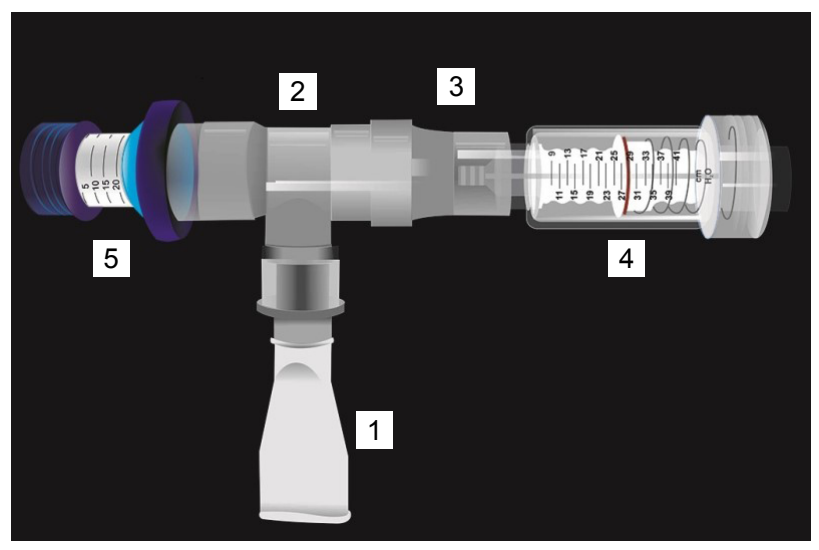

Figure 2 Threshold ${ }^{\circledR}$ IMT device, associated with the PEEP valve used in the study. Notes: I: Mouthpiece; 2: T-piece adapter; 3: unidirectional valve; 4: Threshold ${ }^{\circledR}$ IMT, set at $30 \%$ of MIP; 5: PEEP valve, set at $5 \mathrm{cmH}_{2} \mathrm{O}$.

Abbreviations: IMT, inspiratory muscle training; MIP, maximum inspiratory pressure; PEEP, positive end-expiratory pressure.
The mMRC dyspnea scale was used to evaluate how dyspnea affects the activities of daily living in patients. This scale consists of five items corresponding to the level of dyspnea that limits their activities in daily life. ${ }^{24,30}$

\section{Echocardiography}

The Doppler echocardiographic study included three methods: M-mode, two-dimensional, and Doppler (pulsed, continuous, and color flow mapping). Acuson Cypress Siemens 5.0 echocardiographic equipment (Siemens Medical Solutions, Malvern, PA, USA) with waves ranging from 2.0 to $4.0 \mathrm{MHz}$, was used to perform the tests. Echocardiographic measurements in the M-mode and color flow mapping were obtained according to the criteria established by the American Society of Echocardiography and the European Association of Cardiovascular Imaging. ${ }^{31}$ An expert sonographer evaluated the studies, and all images were recorded and analyzed later.

This was a double-blind examination, since neither the echocardiographer nor the participants were aware of the procedures. During the tests, patients were positioned in the supine and left semi-lateral position and instructed to breathe normally. The E- (fast-filling phase) and A-waves (atrial contraction phase) were evaluated at the tricuspid and mitral valves at three different times in the following sequence: during basal respiration (sham device), during inspiratory overload at $30 \%$ of MIP, and during inspiratory overload in combination with the PEEP valve with $5 \mathrm{cmH}_{2} \mathrm{O}$ (IMT + PEEP).

\section{Statistical analysis}

The sample size was obtained to test the difference between the two means of overload of the inspiratory muscles, with or without the PEEP valve, in healthy volunteers and patients with COPD. We used a significance level of $5 \%$, a power of $90 \%$, and assumed that the variance of the measures of overload of the inspiratory muscles in patients with COPD was two times higher than that of healthy volunteers. Therefore, we obtained the values of 15 healthy subjects and 20 patients with COPD. ${ }^{32}$

The variables are presented as mean \pm standard deviation. The Kolmogorov-Smirnov test was used to assess normality of the data. The paired $t$-test was used to compare the intragroup data of baseline breathing, with overload of the inspiratory muscles and overload of the inspiratory muscles associated with the PEEP valve. The unpaired $t$-test was used to compare the intergroup data. Data analysis was performed using GraphPad Prism version 5.0 (GraphPad Software Inc, La Jolla, CA, USA). The significance level was set at $p<0.05$. 


\section{Results}

Table 1 shows the patients' anthropometric data, pulmonary function, CAT, and mMRC scores, and inspiratory muscle strength. There was no significant difference regarding the sex, age, and height of the subjects included in the study. The values for weight and BMI were significantly lower in the COPD group. Similar results were found for the pulmonary function test, with significantly lower forced vital capacity, $\mathrm{FEV}_{1}$, and Tiffeneau index in participants with COPD. Regarding the severity of COPD, $70 \%$ of the participants were classified as GOLD II or III, $50 \%$ had CAT score $<10$, and $60 \%$ had mMRC score $<2$. The MIP values found in the COPD group were significantly lower than those of the control group.

Table 2 shows the hemodynamic parameters for the mitral valve in both groups during the inspiratory and expiratory phases, at baseline conditions, and with overload of the inspiratory muscles, associated with or without the PEEP valve. The value of the E-waves decreased significantly

Table I Anthropometric data, pulmonary function, CAT, and mMRC scores, and respiratory muscle strength

\begin{tabular}{|c|c|c|c|}
\hline \multirow[t]{2}{*}{ Parameter } & \multirow{2}{*}{$\begin{array}{l}\begin{array}{l}\text { Control } \\
(n=15)\end{array} \\
\text { Mean } \pm \text { SD } \\
\end{array}$} & \multirow{2}{*}{$\begin{array}{l}\text { COPD } \\
(n=20)\end{array}$} & \multirow[t]{2}{*}{$p$-value } \\
\hline & & & \\
\hline Age (years) & $59.33 \pm 6.11$ & $64.45 \pm 7.48$ & 0.054 \\
\hline $\operatorname{Sex}(F / M)$ & $9 / 6$ & $9 / 11$ & 1.54 \\
\hline Weight (kg) & $74.87 \pm 12.18$ & $61.27 \pm 15.84$ & 0.031 \\
\hline Height (cm) & $161.7 \pm 9.23$ & $157.3 \pm 7.55$ & 0.28 \\
\hline $\mathrm{BMI}\left(\mathrm{kg} / \mathrm{cm}^{2}\right)$ & $28.58 \pm 3.55$ & $24.52 \pm 5.027$ & 0.031 \\
\hline $\mathrm{FVC}(\mathrm{L})$ & $3.18 \pm 0.67$ & $2.20 \pm 0.91$ & 0.001 \\
\hline FVC (\% of predicted) & $96.56 \pm 15.35$ & $73.54 \pm 29.91$ & 0.01 \\
\hline $\mathrm{FEV}_{1}(\mathrm{~L})$ & $2.603 \pm 0.59$ & $1.25 \pm 0.66$ & $<0.001$ \\
\hline $\mathrm{FEV}_{1}(\%$ of predicted) & $106.7 \pm 18.99$ & $53.19 \pm 24.71$ & $<0.001$ \\
\hline $\mathrm{FEV}_{1} / \mathrm{FVC}(\%)$ & $0.8 I \pm 0.44$ & $0.55 \pm 0.12$ & $<0.001$ \\
\hline \multicolumn{4}{|l|}{ GOLD, n (\%) } \\
\hline I & - & $3(15)$ & - \\
\hline II & - & $7(35)$ & - \\
\hline III & - & $7(35)$ & - \\
\hline IV & - & $3(15)$ & - \\
\hline \multicolumn{4}{|l|}{ CAT, n (\%) } \\
\hline$<10$ & - & $10(50)$ & - \\
\hline$\geq 10$ & - & $10(50)$ & - \\
\hline \multicolumn{4}{|l|}{ mMRC, n (\%) } \\
\hline$<2$ & - & $12(60)$ & - \\
\hline$\geq 2$ & - & $8(40)$ & - \\
\hline MIP $\left(\mathrm{cmH}_{2} \mathrm{O}\right)$ & $93.4 \pm 29.34$ & $71.2 \pm 20.91$ & 0.02 \\
\hline MIP (\% of predicted) & $1 \mid 4.1 \pm 34.04$ & $80.05 \pm 23.85$ & 0.001 \\
\hline
\end{tabular}

Note: Bold represents statistically significant values.

Abbreviations: BMI, body mass index; CAT, COPD assessment test; COPD, chronic obstructive pulmonary disease; $F$, female; $\mathrm{FEV}_{1}$, forced expiratory volume in I second; FEV,/FVC, Tiffeneau index; FVC, forced vital capacity; GOLD, Global initiative for Chronic Obstructive Lung Disease; M, male; MIP, maximum inspiratory pressure; mMRC, modified Medical Research Council; SD, standard deviation. during the inspiratory phase with the overload of the inspiratory muscles in both groups. These effects were normalized with the addition of the PEEP valve.

Regarding mitral valve flow, during the expiratory phase, the value of the E-waves was significantly reduced with overload of the inspiratory muscles in the COPD group, and the addition of the PEEP valve normalized those measures. In the control group, during the expiratory phase, there was no difference in E-wave values between basal respiration and IMT; however, an increase in E-wave values with IMT + PEEP was observed as compared to IMT alone.

Table 3 shows the same hemodynamic parameters for the tricuspid valve during inspiration and expiration for both groups at baseline conditions, IMT, and IMT + PEEP. In the inspiratory phase, values of the E-waves decreased significantly with the overload of the inspiratory muscles in both groups. These effects were normalized with the addition of the PEEP valve only in COPD group. Regarding tricuspid valve flow, during the expiratory phase, it was observed that the values for the E-waves were significantly reduced with the overload of the inspiratory muscles in both groups. The addition of the PEEP valve normalized these measures.

The intergroup evaluation is depicted in Figure 3. A significant reduction in the E-wave values was observed in the COPD group compared to the control group only at the mitral valve during basal respiration, IMT, and IMT + PEEP procedures, both for inspiration and expiration. At the tricuspid valve, E-wave values were similar in both groups. A-wave values were similar between groups in all situations.

The heart rate (HR) increased significantly in both groups during IMT and IMT + PEEP, during both the inspiratory and expiratory phases. PEEP was found to attenuate the increase in HR imposed by IMT (Table 4).

In the inspiratory phase, HR was significantly higher in the COPD group during IMT compared to the control group. In the expiratory phase, there was a significant increase in HR in the COPD group compared to the control for all three procedures (Figure 4).

When we compared the values of E-waves at the mitral valve during inspiration and expiration, we observed that these were lower in both groups during expiration for basal respiration, IMT, and IMT + PEEP. The A-waves were lower only during basal expiration of the control group compared to inspiration. There was no significant difference in A-wave values between the inspiratory and expiratory phases in the COPD group (Figure 5). With the exception of A-wave during IMT + PEEP in the control group, at the tricuspid valve, both E- and A-wave values were significantly lower during 
Table 2 Echocardiographic parameters evaluated at the mitral valve at baseline conditions, with an overload of the IMT and an overload + PEEP (IMT + PEEP)

\begin{tabular}{|c|c|c|c|c|c|c|c|}
\hline Variable & Group & $\begin{array}{l}\text { Baseline, } \\
\mathrm{cm} / \mathrm{s}\end{array}$ & $\begin{array}{l}\mathrm{IMT}, \\
\mathrm{cm} / \mathrm{s}\end{array}$ & $\begin{array}{l}\text { IMT + PEEP, } \\
\mathrm{cm} / \mathrm{s}\end{array}$ & $\begin{array}{l}p \text {-value } \\
\text { baseline } \times \text { IMT }\end{array}$ & $\begin{array}{l}\text { P-value baseline } \times \\
\text { IMT + PEEP }\end{array}$ & $\begin{array}{l}\text { P-value IMT } \times \\
\text { IMT + PEEP }\end{array}$ \\
\hline \multicolumn{8}{|c|}{ Inspiratory phase } \\
\hline \multirow[t]{2}{*}{ E } & Control & $85.7 \pm 12.5$ & $78.5 \pm 9.0$ & $86.2 \pm 10.1$ & $0.0216^{*}$ & 0.8426 & $0.0168^{\#}$ \\
\hline & COPD & $73.9 \pm 15.3$ & $64.5 \pm 12.0$ & $70.5 \pm 13.4$ & $0.0043^{*}$ & 0.1512 & $0.0038^{\#}$ \\
\hline \multirow[t]{2}{*}{ A } & Control & $82.6 \pm 13.2$ & $80.3 \pm 15.2$ & $80.1 \pm 7.9$ & 0.2168 & 0.4963 & 0.9444 \\
\hline & COPD & $76.5 \pm 18.1$ & $72.6 \pm 13.8$ & $76.1 \pm 12.8$ & 0.2581 & 0.9064 & 0.1262 \\
\hline \multicolumn{8}{|c|}{ Expiratory phase } \\
\hline \multirow[t]{2}{*}{ E } & Control & $78.3 \pm 10.4$ & $75.0 \pm 10.9$ & $81.9 \pm 12.3$ & 0.1976 & 0.1753 & $0.0087^{\#}$ \\
\hline & COPD & $64.3 \pm 13.0$ & $57.6 \pm 11.2$ & $63.8 \pm 12.5$ & $0.0043^{*}$ & 0.7109 & $0.0019^{\#}$ \\
\hline \multirow[t]{2}{*}{ A } & Control & $78.1 \pm 13.5$ & $79.1 \pm 16.6$ & $78.7 \pm 9.4$ & 0.5925 & 0.8305 & 0.9274 \\
\hline & COPD & $75.9 \pm 18.6$ & $73.0 \pm 16.3$ & $75.5 \pm 15.0$ & 0.3588 & 0.8985 & 0.1418 \\
\hline
\end{tabular}

Notes: Data are expressed as mean \pm SD. E: fast-filling phase; A: atrial contraction phase. *IMT compared to basal respiration; \#IMT compared to IMT + PEEP. Abbreviations: COPD, chronic obstructive pulmonary disease; IMT, inspiratory muscles training; PEEP, positive end-expiratory pressure; SD, standard deviation.

expiration compared to inspiration in both groups and for all three procedures (Figure 6).

\section{Discussion}

This study indicates, for the first time, that combination of the PEEP valve with the Threshold IMT $^{\circledR}$ device, with an overload of $30 \%$ of MIP, normalizes the mitral and tricuspid filling velocities as evaluated during the inspiratory and expiratory phases in patients with COPD.

COPD is one of the major causes of morbidity and mortality worldwide, and has very heterogeneous clinical outcomes according to the severity and progression of the disease. ${ }^{33}$ Lee et al evaluated 428 patients with COPD and observed discrepancies between $\mathrm{mMRC}$ and CAT criteria in identifying patients with multiple symptoms. ${ }^{34}$ They concluded that a CAT score $\geq 15$ is a better indicator for the "multiple symptoms group" in the management of patients with COPD. According to the results of the present study, $53 \%$ of patients with COPD had a CAT score $\geq 15$.

Similar to other results from the literature, ${ }^{8}$ patients with COPD in the present study showed a $23 \%$ reduction in MIP compared to the control group, showing a reduction in inspiratory muscle strength in patients with COPD. A systematic review by Geddes et $\mathrm{al}^{35}$ suggests that respiratory muscle training significantly increases the strength and endurance of the inspiratory muscles, improves tolerance to physical activity, and reduces dyspnea in patients with COPD. The optimal intensity for IMT is not known, and different studies suggest the use of an overload of $15 \%-80 \%$ of MIP. ${ }^{36}$ In this study, we used an inspiratory overload of $30 \%$ of MIP, which was the recommended initial resistance in a previous study. ${ }^{36}$ The device used in this study was the

Table 3 Echocardiographic parameters evaluated at the tricuspid valve at baseline conditions, with an overload of the IMT and an overload + PEEP (IMT + PEEP)

\begin{tabular}{|c|c|c|c|c|c|c|c|}
\hline Variable & Group & $\begin{array}{l}\text { Baseline, } \\
\mathrm{cm} / \mathrm{s}\end{array}$ & $\begin{array}{l}\text { IMT, } \\
\mathrm{cm} / \mathrm{s}\end{array}$ & $\begin{array}{l}\text { IMT + PEEP, } \\
\mathrm{cm} / \mathrm{s}\end{array}$ & $\begin{array}{l}p \text {-value } \\
\text { baseline } \times \text { IMT }\end{array}$ & $\begin{array}{l}\text { p-value baseline } \times \\
\text { IMT }+ \text { PEEP }\end{array}$ & $\begin{array}{l}\text { p-value IMT } \times \\
\text { IMT + PEEP }\end{array}$ \\
\hline \multicolumn{8}{|c|}{ Inspiratory phase } \\
\hline \multirow[t]{2}{*}{ E } & Control & $60.1 \pm 6.0$ & $56.2 \pm 7.0$ & $60.1 \pm 7.3$ & $0.040 *$ & 0.9779 & 0.1742 \\
\hline & COPD & $60.6 \pm 7.1$ & $54.0 \pm 7.3$ & $62.1 \pm 8.5$ & $<0.000 I^{*}$ & 0.4829 & $<0.000 I^{\#}$ \\
\hline \multirow[t]{2}{*}{ A } & Control & $54.5 \pm 5.4$ & $53.7 \pm 7.0$ & $52.5 \pm 6.7$ & 0.5908 & 0.2527 & 0.5090 \\
\hline & COPD & $50.1 \pm 6.6$ & $50.3 \pm 8.6$ & $51.9 \pm 9.4$ & 0.9332 & 0.1522 & 0.4288 \\
\hline \multicolumn{8}{|c|}{ Expiratory phase } \\
\hline \multirow[t]{2}{*}{$\mathrm{E}$} & Control & $55.5 \pm 6.4$ & $48.9 \pm 4.4$ & $55.6 \pm 7.6$ & $0.0006 *$ & 0.9773 & $0.0130^{\#}$ \\
\hline & COPD & $52.8 \pm 6.5$ & $48.1 \pm 7.5$ & $54.8 \pm 8.1$ & $0.0004^{*}$ & 0.3091 & $0.0006^{\#}$ \\
\hline \multirow[t]{2}{*}{ A } & Control & $50.9 \pm 5.6$ & $49.5 \pm 8.1$ & $51.5 \pm 6.5$ & 0.3875 & 0.6511 & 0.2632 \\
\hline & COPD & $46.1 \pm 6.8$ & $46.9 \pm 8.4$ & $48.6 \pm 7.1$ & 0.6038 & $0.0449^{\wedge}$ & 0.2587 \\
\hline
\end{tabular}

Notes: Data are expressed as mean \pm SD. E: fast-filling phase; A: atrial contraction phase. *IMT compared to basal respiration, $\wedge$ IMT + PEEP compared to basal respiration, "IMT compared to IMT + PEEP.

Abbreviations: COPD, chronic obstructive pulmonary disease; IMT, inspiratory muscles training; PEEP, positive end-expiratory pressure; COPD, chronic obstructive pulmonary disease; SD, standard deviation. 
Inspiration
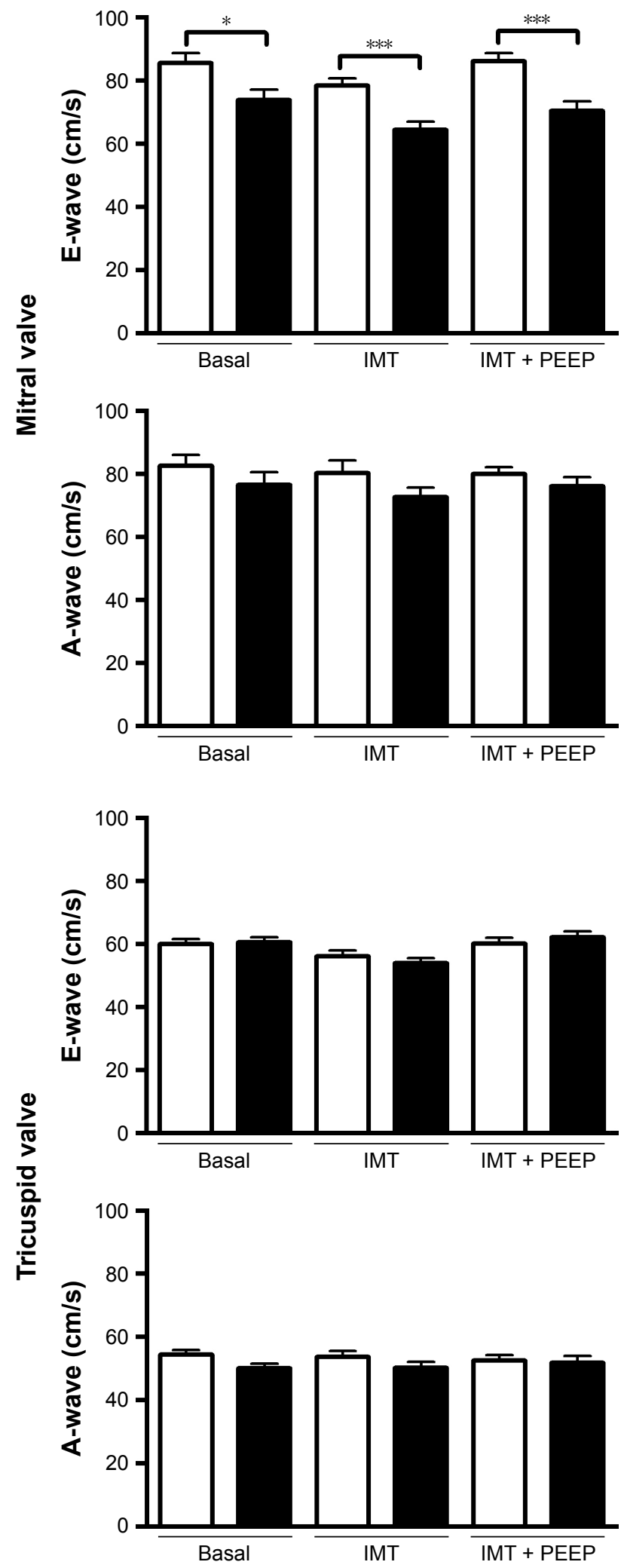

Expiration
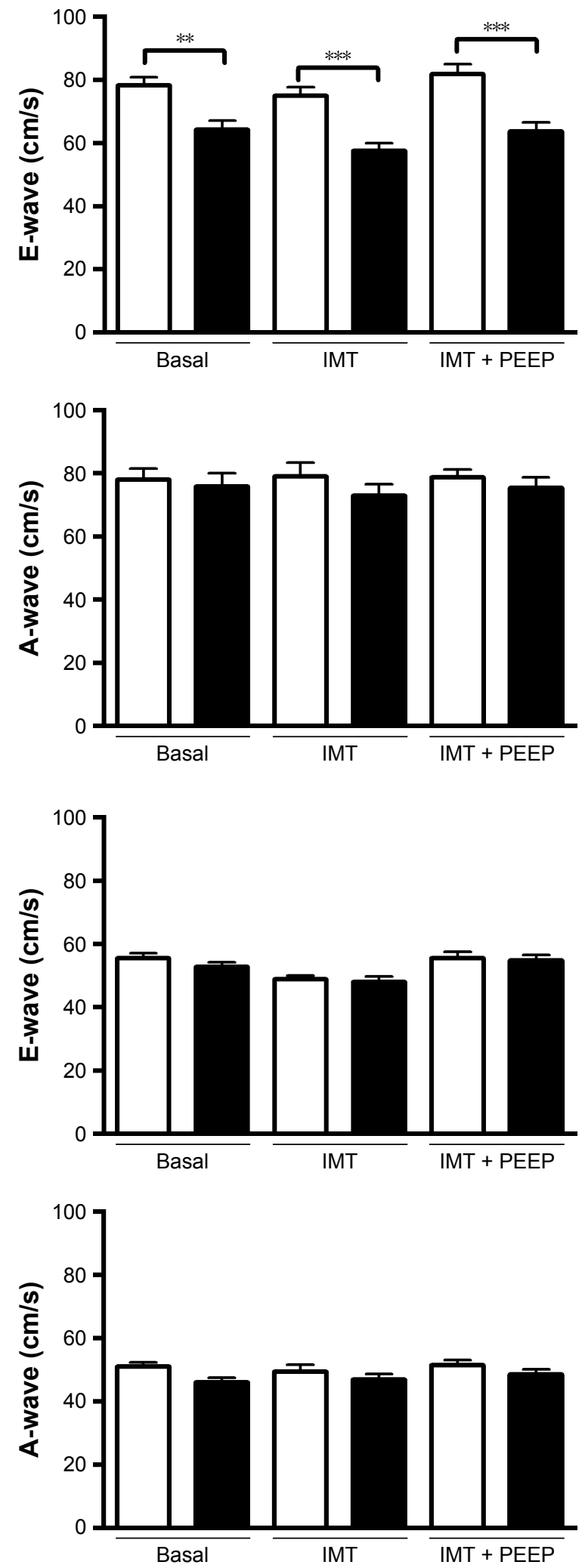

Figure 3 Echocardiographic parameters of the control (white bars) and COPD (black bars) groups during basal respiration with IMT overload and inspiratory overload associated with the PEEP valve (IMT + PEEP).

Notes: $* p<0.05 ; * * p<0.01 ; * * * p<0.001$.

Abbreviations: COPD, chronic obstructive pulmonary disease; IMT, inspiratory muscle training; PEEP, positive end-expiratory pressure. 
Table 4 Changes in participants' heart rate during the inspiratory and expiratory phases in the experimental and control groups during basal respiration, with an overload of the IMT, and an overload of the inspiratory muscles associated with the PEEP valve (IMT + PEEP)

\begin{tabular}{lllllll}
\hline Group & $\begin{array}{l}\text { Basal, } \\
\text { bpm }\end{array}$ & $\begin{array}{l}\text { IMT, } \\
\text { bpm }\end{array}$ & $\begin{array}{l}\text { IMT }+ \text { PEEP, } \\
\text { bpm }\end{array}$ & $\begin{array}{l}\text { p-value } \\
\text { basal } \times \text { IMT }\end{array}$ & $\begin{array}{l}\text { p-value basal } \times \\
\text { IMT }+ \text { PEEP }\end{array}$ & $\begin{array}{l}\text { P-value IMT } \times \\
\text { IMT + PEEP }\end{array}$ \\
\hline $\begin{array}{l}\text { Inspiratory phase } \\
\text { Control }\end{array}$ & $66 \pm 2$ & $69 \pm 2$ & $68 \pm 2$ & $<0.000 I^{*}$ & $0.0046^{\wedge}$ & $0.0002^{\#}$ \\
$\begin{array}{l}\text { COPD } \\
\text { Expiratory phase }\end{array}$ & $68 \pm 3$ & $73 \pm 5$ & $70 \pm 5$ & $<0.000 I^{*}$ & $0.0005^{\wedge}$ & $0.0009^{\#}$ \\
$\quad \begin{array}{l}\text { Control } \\
\text { COPD }\end{array}$ & $69 \pm 3$ & $73 \pm 3$ & $71 \pm 3$ & & & $<0.000 I^{\#}$ \\
\hline
\end{tabular}

Notes: Data are expressed as mean \pm SD. *IMT compared to basal respiration, ^IMT + PEEP compared to basal respiration, \#IMT compared to IMT + PEEP.

Abbreviations: COPD, chronic obstructive pulmonary disease; IMT, inspiratory muscles training; PEEP, positive end-expiratory pressure; SD, standard deviation.

Threshold IMT ${ }^{\circledR}$, widely recommended for strengthening of the inspiratory muscles..$^{20,35,37}$

Chronic pulmonary diseases can alter left and right ventricular function owing to pulmonary hyperinflation, increased pulmonary vascular resistance, and increased negative intrathoracic pressure generation. ${ }^{38}$ In the present study, we postulated that overloading of the inspiratory muscles would promote changes in the ventricular filling patterns due to increased intrapleural negativity, and that the PEEP valve could modulate this effect. In patients with COPD, the main effect of the PEEP valve is an increase in expiratory flow and reduction in pulmonary hyperinflation. ${ }^{21,22}$ The external PEEP extends the expiratory time and reduces respiratory frequency, reducing airway collapse and therefore dynamic hyperinflation. ${ }^{21}$ The reduction of PEEPi reduces the inspiratory threshold and consequently reduces the workload of inspiratory muscles.

The echocardiographic parameters evaluated were the E- and A-waves, which respectively correspond to the rapid ventricular filling phase and atrial contraction. In the present study, we observed a significant reduction in mitral inflow during IMT, as measured via the E-waves, in both groups.
Our data are in accordance with Cheyne et al who reported that an increase of $-20 \mathrm{cmH}_{2} \mathrm{O}$ in intrapleural pressure resulted in a reduction of left ventricle systolic volume at the expense of a reduction of left ventricular diastolic volume, probably due to interventricular interaction. ${ }^{38}$ The increased negative intrathoracic pressure imposed by the overload of inspiratory muscles increases the left ventricular afterload, since it increases left ventricle transmural pressure, thus, reducing the cardiac output. ${ }^{39}$ Yuan et $\mathrm{al}^{15}$ also reported that the pressure on the right side of the heart is greater than that on the left during inspiration with overload, which moves the interventricular septum to the left and thus impairs left ventricular filling. The addition of the PEEP valve normalized these measurements, probably by attenuating the increase in negativity of pleural pressure imposed by inspiratory muscle overload and simultaneously by reducing afterload of the left ventricle. Similar results were observed for the tricuspid valve in patients with COPD. IMT reduced the E-waves in patients with COPD during both the inspiratory and expiratory phase. Association of the PEEP valve with overload of the inspiratory muscles also normalized the E-wave values.
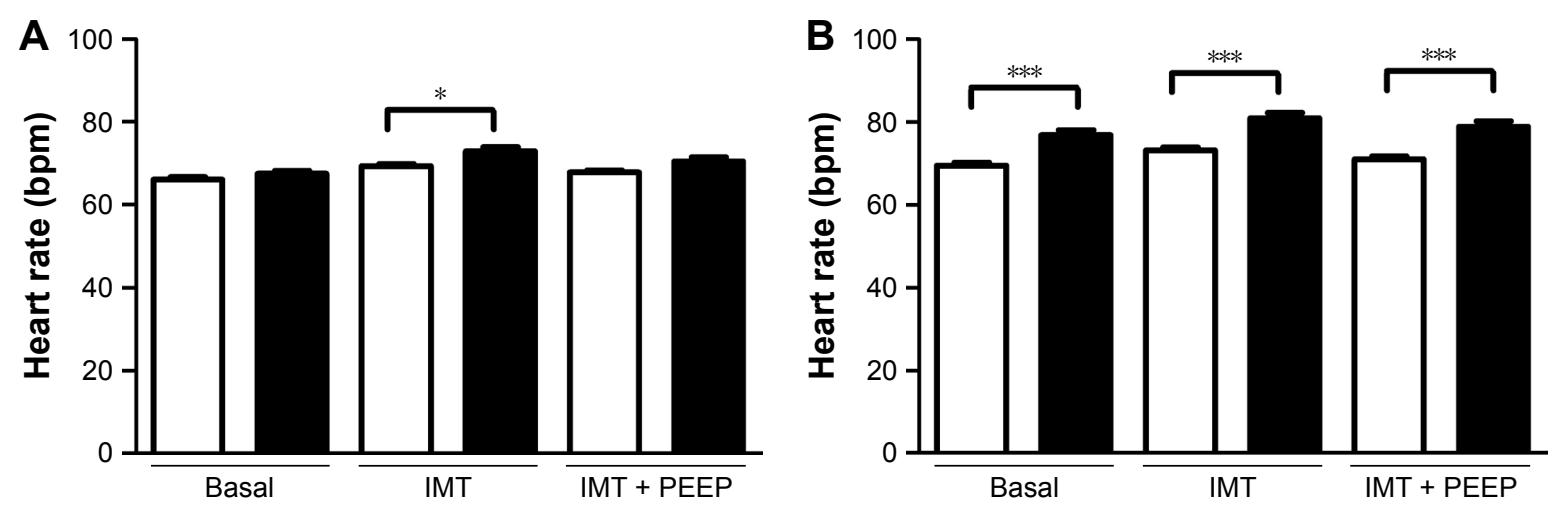

Figure 4 HR in the control (white bars) and COPD groups (black bars) during basal respiration, overload of IMT, and overload of inspiratory muscle associated with the PEEP valve (IMT + PEEP), in the inspiratory $(\mathbf{A})$ and expiratory $(\mathbf{B})$ phases.

Notes: ${ }^{*} p<0.05 ; * * * p<0.001$.

Abbreviations: COPD, chronic obstructive pulmonary disease; IMT, inspiratory muscle training; PEEP, positive end-expiratory pressure; HR, heart rate. 

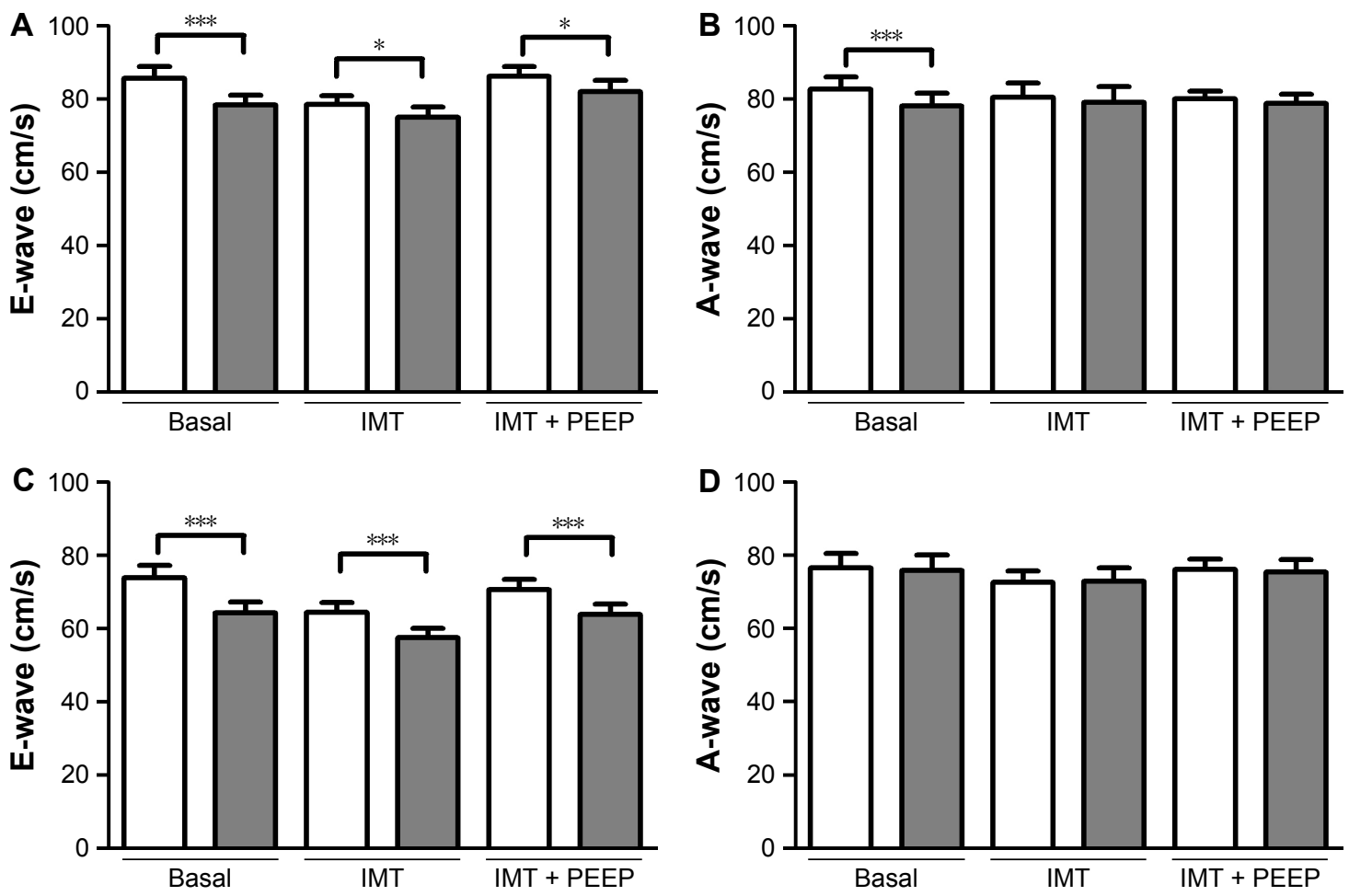

Figure 5 Analysis of E- and A-waves during inspiratory phase (white bars) and expiratory phase (gray bars) at the mitral valve in the control group (A and B) and COPD group ( $\mathbf{C}$ and $\mathbf{D}$ ) during basal respiration, overload of IMT, and overload of inspiratory muscles associated with the PEEP valve (IMT + PEEP).

Notes: $* p<0.05 ; * * *<0.001$.

Abbreviations: COPD, chronic obstructive pulmonary disease; IMT, inspiratory muscle training; PEEP, positive end-expiratory pressure.
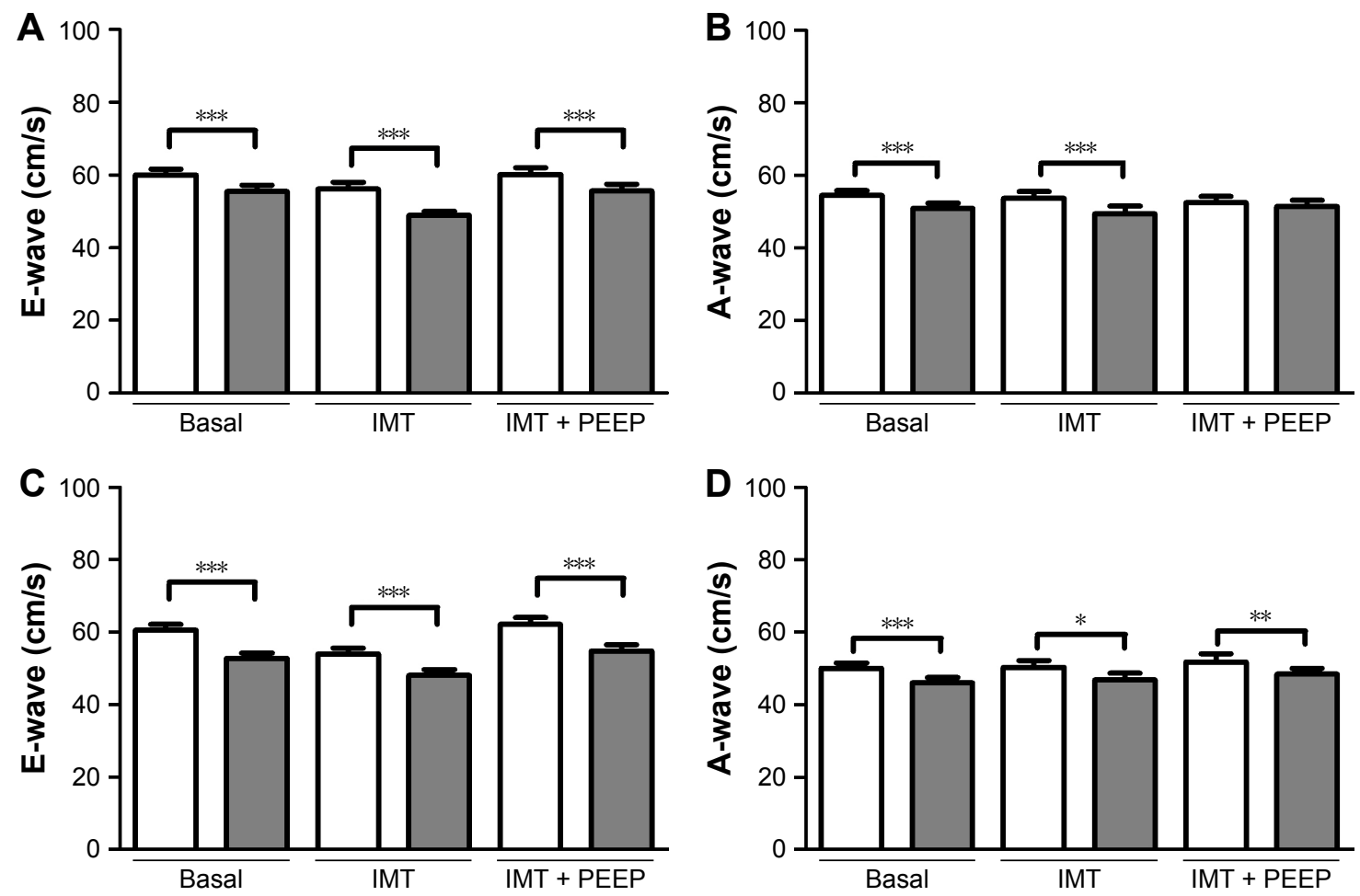

Figure 6 Analysis of E- and A-waves during inspiratory phase (white bars) and expiratory phase (gray bars) at the tricuspid valve in the control group (A and B) and COPD group ( $\mathbf{C}$ and $\mathbf{D}$ ) during basal respiration, overload of IMT, and overload of inspiratory muscles associated with the PEEP valve (IMT + PEEP).

Notes: ${ }^{*} p<0.05 ; * * p<0.01 ; * * * p<0.001$.

Abbreviations: COPD, chronic obstructive pulmonary disease; IMT, inspiratory muscle training; PEEP, positive end-expiratory pressure. 
Comparing the two groups, we observed that the COPD group had lower E-wave values in both inspiration and expiration during the three procedures, but only at the mitral valve. Hyperinflation is related to an impaired left ventricular diastolic filling pattern, and this dysfunction seems to be related to a reduced preload. ${ }^{40}$ Another possible reason for the reduction in E-waves in patients with COPD is increased afterload of the right ventricle induced by pulmonary hyperinflation and PEEPi, reducing right ventricular stroke volume and inducing left ventricular hypo-filling. ${ }^{41}$ Increased negative intrapleural pressure also increases left ventricular afterload by increasing aortic transmural pressure. We also observed that the HR of the COPD group, in the inspiratory phase, was significantly higher during IMT compared to the control group. In contrast, in the expiratory phase, HR in the COPD group was higher than that in the control group during basal respiration, IMT, and IMT + PEEP. This increase in HR can be attributed to the autonomic dysfunction of HR in this population. Patients with COPD have impaired sympathetic-vagal balance, and changes in the autonomic control of HR are associated with loss of strength in the inspiratory muscles. ${ }^{42,43}$

In the present study, there were no changes in the atrial contraction phase (A-wave) in the control group during basal respiration, IMT, and IMT + PEEP, in both the inspiratory and expiratory phases of mitral and tricuspid valve flow. Similar results were observed in patients with COPD. With the exception of the IMT + PEEP treatment that significantly increased the A-wave in relation to basal respiration, as evaluated at the tricuspid valve during the expiratory phase, the other parameters did not change. These results suggest that overload of the respiratory muscles did not affect the late filling of the right and left ventricles.

According to Verhoeff and Mitchell, ${ }^{44}$ under normal conditions, the right ventricle receives slightly more volume during inspiration due to the decreased thoracic pressure. In the current study, we demonstrate that the E-wave values were significantly lower during expiration at the tricuspid and mitral valves in both groups and for all three procedures. Our findings are consistent with those of Verhoeff and Mitchell in showing that the passive phase of fast filling is decreased during the expiratory phase in both the control and COPD groups during both normal conditions and when inspiratory load is added, with and without PEEP. These results suggest that the attenuated negative intrathoracic pressure in the expiratory phase, compared to the inspiratory phase, affected the E-wave in the mitral and tricuspid valves similarly in both the control and COPD groups. In contrast, in the mitral valve of the control group, the A-wave was lower only during basal expiration when compared to inspiration. In the tricuspid valve, the A-wave was lower during the expiratory phase under baseline conditions and with added inspiratory load. These results suggest that the attenuated negative intrathoracic pressure in the expiratory phase, compared to the inspiratory phase, has a greater impact on patients with COPD, especially at the tricuspid valve.

The present study has a number of strengths. This was a controlled study and the sample size was sufficient to detect hemodynamic changes induced by overloading of the inspiratory muscles associated or not with external PEEP. In addition, the mitral and tricuspid inflows were evaluated during both inspiratory and expiratory phases using echocardiography, which can help in the accurate estimation of cardiac hemodynamics. However, the study also has some limitations that should be considered. We did not measure static hyperinflation (inspiratory capacity/total lung capacity) that shows associations with cardiac chamber size, impaired left ventricular diastolic filling pattern, and myocardial performance. ${ }^{40} \mathrm{PEEP}$ was set at $5 \mathrm{cmH}_{2} \mathrm{O}$ for all patients instead of being dictated by individual PEEPi. PEEPi is routinely evaluated under static conditions by occluding the airway at end-expiration. However, this measurement is difficult during spontaneous breathing due to expiratory muscle activity and increased respiratory frequency. In this case, PEEPi can be measured by the difference between the maximum airway opening and maximum esophageal pressure, obtained with a Muller maneuver from the endexpiratory volume..$^{45}$ However, the need for placement of an esophageal balloon makes PEEPi difficult to measure in clinical practice. MIP was measured in the sitting position to determine overload of the inspiratory muscles, but during echocardiography the participants were in the left semi-lateral position. Studies show that body position influences inspiratory muscle strength in both young healthy subjects ${ }^{46}$ and patients with COPD. ${ }^{47}$ Thus, the $30 \%$ loading of the MIP used during the echocardiographic examination may have been overestimated relative to that which would be assessed in the sitting position. Subjects positioned in left lateral recumbency would be at a respiratory disadvantage because of decreased compliance of the thoracic cage. Another limitation is the overload of the inspiratory muscles established using $30 \%$ of MIP. Literature suggests the use of an overload of $15 \%-80 \%$ of MIP. Future combinations of additional loads, along with additional PEEP levels, will help us make more definitive conclusions. 
In conclusion, we demonstrated that the acute hemodynamic effects induced by overload of the inspiratory muscles were attenuated and/or reversed by the inclusion of an external PEEP valve. The reduction of E-wave, used to measure preload of the ventricles, can affect systemic oxygen delivery $\left(\mathrm{DO}_{2}\right)$, which is calculated as a product of cardiac output, and arterial oxygen content $\left(\mathrm{CaO}_{2}\right)$. Cardiac output is calculated as the product of HR and systolic volume, which depends on preload, afterload, and myocardial contractility. The results of the current study might indicate that E-wave reduction affects $\mathrm{DO}_{2}$, by adding inspiratory load, and can be normalized by adding PEEP.

\section{Acknowledgments}

This work was supported by the Fundação Educacional Lucas Machado - FELUMA, Faculdade Ciências MédicasMinas Gerais, Pós-Graduação em Ciências da Saúde and Conrad - Diagnóstico por Imagem. JFP received support from the Coordenação de Aperfeiçoamento de Pessoal de Nível Superior - CAPES/Brazil. We are grateful to Isabel Cristina Gomes for statistical analysis assistance.

\section{Disclosure}

The authors report no conflicts of interest in this work.

\section{References}

1. Pepe PE, Marini JJ. Occult positive end-expiratory pressure in mechanically ventilated patients with airflow obstruction: the auto-PEEP effect. Am Rev Respir Dis. 1982;126:166-170.

2. Mughal MM, Culver DA, Minai OA, Arroliga AC. Auto-positive endexpiratory pressure: mechanisms and treatment. Cleve Clin JMed. 2005; 72:801-809

3. Varga J. Mechanisms to dyspnoea and dynamic hyperinflation related exercise intolerance in COPD. Acta Physiol Hung. 2015;102:163-175.

4. Marini JJ. Dynamic hyperinflation and auto-positive end-expiratory pressure. Lessons learned over 30 years. Am J Respir Crit Care Med. 2011;184:756-762.

5. Aldrich TK, Hendler JM, Vizioli LD, Park M, Multz AS, Shapiro SM. Intrinsic positive end-expiratory pressure in ambulatory patients with airways obstruction. Am Rev Respir Dis. 1993;147:845-849.

6. O’Donoghue FJ, Catcheside PG, Jordan AS, Bersten AD, McEvoy RD. Effect of CPAP on intrinsic PEEP, inspiratory effort, and lung volume in severe stable COPD. Thorax. 2002;57:533-539.

7. González C, Servera E, Marín J. Importance of noninvasively measured respiratory muscle overload among the causes of hospital readmission of COPD patients. Chest. 2008;133:941-947.

8. Newell SZ, McKenzie DK, Gandevia SC. Inspiratory and skeletal muscle strength and endurance and diaphragmatic activation in patients with chronic airflow limitation. Thorax. 1989;44:903-912.

9. Orozco-Levi M. Structure and function of the respiratory muscles in patients with COPD: impairment or adaptation? Eur Respir J. 2003;46: $41 \mathrm{~s}-51 \mathrm{~s}$

10. Gea J, Agustí A, Roca J. Pathophysiology of muscle dysfunction in COPD. J Appl Physiol. 2013;114:1222-1234.

11. Rahaghi FN, van Beek EJ, Washko GR. Cardiopulmonary coupling in chronic obstructive pulmonary disease. J Thorac Imaging. 2014;29: 80-91.
12. Vonk-Noordegraaf A, Marcus T, Holverda S, Roseboom B, Postmus PE. Early changes of cardiac structure and function in COPD patients with mild hypoxemia. Chest. 2005;127:1898-1903.

13. Matthay RA, Arroliga AC, Wiedermann HP, Schulman DS, Mahler DA. Right ventricular function at rest and during exercise in chronic obstructive pulmonary disease. Chest. 1992;101: $255 \mathrm{~S}-262 \mathrm{~S}$

14. Byeon K, Choi JO, Yang JH, et al. The response of the vena cava to abdominal breathing. J Altern Complement Med. 2012;18:153-157.

15. Yuan L, Cao T, Duan Y, Yang G, Wang Z, Ruan L. Noninvasive assessment of influence of resistant respiration on blood flow velocities across the cardiac valves in humans - a quantification study by echocardiography. Echocardiography. 2004;21:391-398.

16. Mandysová E, Nierdele P. Influence of load changes on tricuspid inflow Physiol Res. 2007;56:299-305.

17. Houben-Wilke S, Spruit MA, Uszko-Lencer NH, et al. Echocardiographic abnormalities and their impact on health status in patients with COPD referred for pulmonary rehabilitation. Respirology. 2017; 22(5):928-934.

18. Neves LF, Reis MH, Plentz RD, Matte DL, Coronel CC, Sbruzzi G. Expiratory and expiratory plus inspiratory muscle training improves respiratory muscle strength in subjects with COPD: systematic review. Respir Care. 2014;59:1381-1388.

19. Ramírez-Sarmiento A, Orozco-Levi M, Barreiro E, et al. Expiratory muscle endurance in chronic obstructive pulmonary disease. Thorax. 2002;57:132-136.

20. Gosselink R, De Vos J, van den Heuvel SP, Segers J, Decramer M, Kwakkel G. Impact of inspiratory muscle training in patients with COPD: what is the evidence? Eur Respir J. 2011;37:416-425.

21. Nicolini A, Merliak F, Barlascini C. Use of positive expiratory pressure during six minute walk test: results in patients with moderate to severe chronic obstructive pulmonary disease. Multidiscip Respir Med. 2013;8:19.

22. Monteiro MB, Berton DC, Moreira MA, Menna-Barreto SS, Teixeira PJ. Effects of expiratory positive airway pressure on dynamic hyperinflation during exercise in patients with COPD. Respir Care. 2012;57: 1405-1412.

23. Global Initiative for Chronic Obstructive Lung Disease (GOLD). Global strategy for the diagnosis, management, and prevention of COPD, updated 2015. Available from: http://goldcopd.org/.

24. Kovelis D, Segretti NO, Probst VS, Lareau SC, Brunetto AF, Pitta F. Validation of the Modified Pulmonary Functional Status and Dyspnea Questionnaire and the Medical Research Council scale for use in Brazilian patients with chronic obstructive pulmonary disease. J Bras Pneumol. 2008;34:1008-1018.

25. Silva GP, Morano MT, Viana CM, Magalhães CB, Pereira ED. Portuguese-language version of the COPD Assessment Test: validation for use in Brazil. J Bras Pneumol. 2013;39:402-408.

26. Miller MR, Hankinson J, Brusasco V, et al. Standardisation of spirometry. Eur Respir J. 2005;26:319-338.

27. Pereira CA, Sato T, Rodrigues SC. New reference values for forced spirometry in white adults in Brazil. J Bras Pneumol. 2007;33: $397-406$.

28. Pereira CAC. Espirometria. J Pneumol. 2002;8(Suppl 3):S1-82.

29. Jones PW, Harding G, Berry P, Wiklund I, Chen WH, Kline Leidy N. Development and first validation of the COPD Assessment Test. Eur Respir J. 2009;34:648-654.

30. Stenton C. The MRC breathlessness scale. Occup Med (Lond). 2008; 58:226-227

31. Lang RM, Badano LP, Mor-Avi V, et al. Recommendations for cardiac chamber quantification by echocardiography in adults: an update from the American Society of Echocardiography and the European Association of Cardiovascular Imaging. J Am Soc Echocardiogr. 2015;28: $1-39$.

32. Luh WM, Guo JH. Approximate sample size formulas for the twosample trimmed mean test with unequal variances. Br J Math Stat Psychol. 2007;60:137-146. 
33. Moreira GL, Donária L, Furlanetto KC, et al. GOLD B-C-D groups or GOLD II-III-IV grades: which one better reflects the functionality of patients with chronic obstructive pulmonary disease? Chron Respir Dis. 2015;12:102-110.

34. Lee CH, Lee J, Park YS, et al. Chronic obstructive pulmonary disease (COPD) assessment tests scores corresponding to modified Medical Research Council grades among COPD patients. Korean J Intern Med. 2015;30(5):629-637.

35. Geddes EL, O'Brien K, Reid WD, Brooks D, Crowe J. Inspiratory muscle training in adults with chronic obstructive pulmonary disease: an update of a systematic review. Respir Med. 2008;102:1715-1729.

36. Lee AL, Holland AE. Time to adapt exercise training regimens in pulmonary rehabilitation - a review of the literature. Int J Chron Obstruct Pulmon Dis. 2014;9:1275-1288.

37. Hill K, Cecins NM, Eastwood PR, Jenkins SC. Inspiratory muscle training for patients with chronic obstructive pulmonary disease: a practical guide for clinicians. Arch Phys Med Rehabil. 2010;91:1466-1470.

38. Cheyne WS, Williams AM, Harper MI, Eves ND. Heart-lung interaction in a model of COPD: importance of lung volume and direct ventricular interaction. Am J Physiol Heart Circ Physiol. 2016; 311(6):H1367-H1374.

39. Karam M, Wise RA, Natarajan TK, Permutt S, Wagner HN. Mechanism of decreased left ventricular stroke volume during inspiration in man. Circulation. 1984;69:866-873.

40. Watz H, Waschki B, Meyer T, et al. Decreasing cardiac chamber sizes and associated heart dysfunction in COPD: role of hyperinflation. Chest. 2010;138:32-38.
41. Watz H, Waschki B, Magnussen H. Emphysema, airflow obstruction, and left ventricular filling. N Engl J Med. 2010;362(17):1638-1639.

42. Reis MS, Arena R, Deus AP, Simões RP, Catai AM, Borghi-Silva A. Deep breathing heart rate variability is associated with respiratory muscle weakness in patients with chronic obstructive pulmonary disease. Clinics (Sao Paulo). 2010;65:369-375.

43. van Gestel AJ, Kohler M, Clarenbach CF. Sympathetic overactivity and cardiovascular disease in patients with chronic obstructive pulmonary disease. Discov Med. 2012;14(79):359-368.

44. Verhoeff K, Mitchell JR. Cardiopulmonary physiology: why the heart and lungs are inextricably linked. Adv Physiol Educ. 2017;41(3): 348-353.

45. Purro A, Appendini L, Patessio A, et al. Static intrinsic PEEP in COPD patients during spontaneous breathing. Am J Respir Crit Care Med. 1998;157(4 pt 1):1044-1050.

46. Costa R, Almeida N, Ribeiro F. Body position influences the maximum inspiratory and expiratory mouth pressures of young healthy subjects. Physiotherapy. 2015;101(2):239-241.

47. Heijdra YF, Dekhuijzen PN, van Herwaarden CL, Folgering HT. Effects of body position, hyperinflation, and blood gas tensions on maximal respiratory pressures in patients with chronic obstructive pulmonary disease. Thorax. 1994;49(5):453-458.
International Journal of COPD

\section{Publish your work in this journal}

The International Journal of COPD is an international, peer-reviewed journal of therapeutics and pharmacology focusing on concise rapid reporting of clinical studies and reviews in COPD. Special focus is given to the pathophysiological processes underlying the disease, intervention programs, patient focused education, and self management protocols.

\section{Dovepress}

This journal is indexed on PubMed Central, MedLine and CAS. The manuscript management system is completely online and includes a very quick and fair peer-review system, which is all easy to use. Visit $\mathrm{http}: / / \mathrm{www}$.dovepress.com/testimonials.php to read real quotes from published authors. 